\title{
Motor vehicle crashes and spinal injury
}

\author{
E C Wigglesworth DAppSc DipEd
}

Executive Director, The Menzies Foundation, 210 Clarendon Street, East Melbourne 3002, Australia.

Accident reports for 67 patients admitted to 3 spinal cord injury units in Australia in 1987 as a result of motor vehicle accidents were examined. Two thirds of the accidents occurred during the Friday-Saturday-Sunday leisure period and about $60 \%$ occurred during the November-February Australian summer holiday season. This conforms to the general Australian pattern of road trauma which is predominantly a consequence of leisure travel. The likelihood of a road traffic injury resulting in damage to the spinal cord was highest for motorcyclists whose average age was 22.7 , lower than that for vehicle drivers (33.7) and vehicle passengers (38.1). However the most important finding is that most car occupants received their injuries when a motor vehicle overturned. As vehicle rollovers are relatively rare in the total spectrum of traffic crashes this distribution is thought not to have been previously reported. Some possible mechanisms of spinal cord injury are reviewed and engineering solutions to prevent future injuries are recommended. The paper also emphasises the unique opportunity for Australia to collect meaningful data on the causes of spinal injury and advocates the creation of an Australian Spinal Cord Injury Registry.

Key words: spinal injury; motor vehicle crashes; mechanisms; prevention.

\section{Introduction}

In 1987 the Sir Robert Menzies National Foundation responded positively to a request from Sir George Bedbrook, the Director of the Spinal Injuries Unit, Royal Perth Rehabilitation Hospital, to sponsor a scientific meeting to review ways and means of reducing in Australia the incidence of spinal cord injury, the most debilitating of all forms of injury. Participants included the directors of most spinal cord injury units, senior government officers and leading academics working in the field. They concluded that spinal injury is a harsh, persistent and multisystem disability involving not only mobility but special systems of bladder, bowel and sexual function. There was a further consensus that "with cure still decades away and even then costly, prevention is essential both in terms of human suffering and in economic advantage'. ${ }^{1}$

One presentation to the workshop consisted of a review of 25 papers published in the scientific literature in the period 1966-1986. It identified 19 where attribu- tion of cause had been attempted. The percentage attributed to motor vehicle accidents ranged from $36 \%$ to $69 \%$, with 15 of the 19 papers reporting a narrower range between $41 \%$ and $59 \% .^{2}$ It was therefore suggested that about half of all spinal cord injuries arose as a consequence of road traffic accidents. During the workshop, there was a wide measure of agreement from the spinal injuries unit directors that this was a reasonable reflection of the position in Australia.

However, such evidence as was available seemed to suggest that the incidence of spinal injury in Australia was not decreasing over time. This was particularly disappointing when viewed in the light of the major reduction in road trauma in Australia in recent years. In 1970, the number of Australians killed in road traffic accidents was 3,798 at a rate of 30.4 per 100,000 population. In 1987, the equivalent data were 2,772 deaths at a rate of $15.3 .{ }^{3}$ Sadly, this $50 \%$ improvement seems not to be reflected in a lower incidence of spinal cord injury. In- 
deed, and despite the early promise of the effectiveness of seat belt legislation in reducing the incidence of spinal cord injury, ${ }^{4}$ the converse seems true. Some early reports estimated the incidence of spinal cord injury in Australia to be slightly below 20 per million population. ${ }^{5,6}$ In a later report, Burke $^{7}$ estimated a somewhat higher rate of 23.0, whilst in 1987 the estimate was for an incidence rate of 27.6. ${ }^{8}$ No explanation for this trend was offered to the meeting, but the need for further research was stressed.

It was realised by the present author that some data which could throw light on this subject already existed. The police traffic accident reports on those accidents which resulted in spinal injury had been prepared at the time of each accident and examination of those records would identify the type of crash which caused spinal injury as well as providing some additional information. Such a review would go far to meet the 2 requirements suggested by Mackay: ${ }^{9}$ 'first, frequency information ... of the circumstances of the collision, .... and, secondly, on the mechanisms which cause the injuries

\section{Method}

An initial examination of police accident records in Western Australia produced some quite exceptional figures. Almost three quarters of the persons who were admitted to the Royal Perth Rehabilitation Hospital in 1987 as a consequence of car crashes had been involved in one particular type of crash, a vehicle rollover.

A request was then made for similar information from units in 3 other States, but 3 methodological problems emerged. The first stemmed from the fact that very few road traffic crashes (thankfully) result in spinal injury.

In New South Wales, for example, there are about 60,000 recorded crashes annually, including 20,000 injury crashes (Road Traffic Crashes in New South Wales, Traffic Authority of NSW, annual) but only about 50 of these result in spinal cord injury. To identify these cases, the principal linkage between admission to a spinal injuries unit and the corresponding police report is the name of the patient. This poses linkage difficulties since, in many cases, the accident records are retrieved either through the name of the person killed or through the name of the vehicle driver. In the first case, the system misses those crashes where the person(s) killed differs from the person(s) who suffered spinal injury: in the second case the system misses those crashes where the passenger rather than the driver suffers spinal injury.

This methodological problem was so great that in one State-Queensland - the task of trying to match the names of the persons admitted to the spinal injuries unit with the names on the police traffic accident reports proved not possible and the request was abandoned.

The second problem was that of access to the appropriate accident reports. In New South Wales the intervention of the privacy committee delayed access to the NSW data for more than two years. That is why this paper, offered for publication in 1992, relates to the data for 1987.

Eventually, a total of 93 patients was identified as having been admitted to spinal injuries units as a consequence of motor vehicle accidents in Western Australia, Victoria and New South Wales during 1987. For these accidents, matching police accident reports were found in 74 cases. However, when the data were obtained, they generally consisted of the de-identified police reports.

This produced the third problem. In 7 cases, there had been multiple occupants of a car from the same family and with the same surname. In those cases, the de-identification process made it impossible to distinguish which car occupant had suffered spinal injury. These cases were removed, leaving a total of 67 cases. This study is based on the police accident reports of those 67 cases which were used to tabulate information about the type of road user, the age and sex of the person injured, the day and month of the accident, and, most importantly, about the type of crash.

\section{Results}

Type of road user

Of the 67 cases, 4 related to pedestrians, 3 
male and one female, with ages ranging from 10 to 75 . A fifth case related to a 30 year old male bicyclist. As the purpose of this paper was to review the relationship between motor vehicle crashes and spinal cord injury, these cases are not considered further and the analysis is confined to the remaining 62 cases. Of these, 18 were motorcyclists, 32 were motor vehicle drivers and 12 motor vehicle passengers. Details are given in Table I.

\section{Day and month}

Injuries by day of week are shown in Figure 1 and injuries by month of year in Figure 2 . These histograms show that almost two thirds of the weekday cases arose in the Friday-Saturday-Sunday leisure period, and about $60 \%$ of the monthly cases arose in the summer holiday months of NovemberFebruary

\section{Type of crash}

The type of crash was analysed in accordance with the Coding of Road User Movements developed by the Victorian Road Safety and Traffic Authority. ${ }^{10}$ This coding, now entitled 'Definitions for Classifying Accidents', consists of a $10 \times 10$ matrix with a 2 digit number identifying head-on crashes, rear-end collisions, right turn sideswipes and so forth. The categories of interest in this study were those numbered 170-173. These are defined thus:

Code 170 Vehicle travelled off the road to the left and rolled over.
Code 171 Vehicle travelled off the road to the left, rolled over and hit fixed object.

Code 172 Vehicle travelled off the road to the right and rolled over.

Code 173 Vehicle travelled off the road to the right, rolled over and hit fixed object.

For motor vehicle occupants, Table II shows that, of the total of 44 crashes, no less than 38 occurred as a consequence of

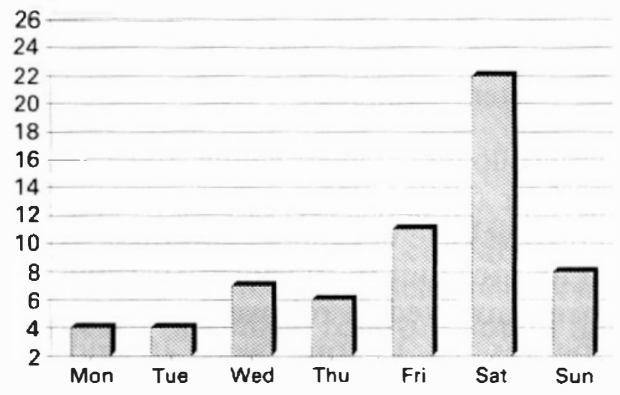

Figure 1 Injuries by day of week

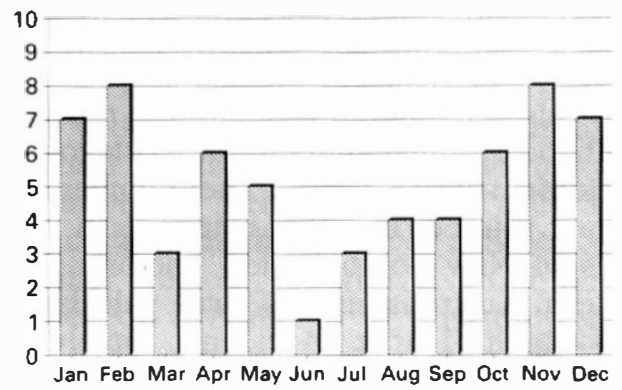

Figure 2 Injuries by month of year

Table I Types and characteristics of road users

\begin{tabular}{lccc}
\hline & Motor vehicle drivers & $\begin{array}{c}\text { Motor vehicle } \\
\text { passengers }\end{array}$ & Motor cyclists \\
\hline Males & 23 & 8 & 16 \\
Females & 9 & 4 & $2^{\mathrm{a}}$ \\
Persons & 32 & 12 & 18 \\
Wearing seat belts & 14 & 9 & $\mathrm{n} / \mathrm{a}$ \\
Not wearing seat belts & 6 & 1 & $\mathrm{n} / \mathrm{a}$ \\
Not reported & 12 & 2 & $\mathrm{n} / \mathrm{a}$ \\
Age range & $17-77$ & $18-69$ & $18-28$ \\
Mean age & 33.7 & 38.1 & 22.7 \\
\hline
\end{tabular}

${ }^{a}$ both pillion passengers 
Table II Motor vehicle occupants suffering spinal injury

\begin{tabular}{|c|c|c|c|c|c|c|c|c|}
\hline \multicolumn{2}{|c|}{ Motor vehicle rollovers } & \multirow[t]{2}{*}{ Number of cases } & \multicolumn{3}{|c|}{ Metropolitan } & \multicolumn{3}{|c|}{ Non Metropolitan } \\
\hline & & & NSW & VIC & WA & NSW & VIC & WA \\
\hline \multirow{4}{*}{ Code } & 170 & 9 & - & - & - & 2 & 3 & 4 \\
\hline & 171 & 10 & 2 & 1 & - & 2 & 4 & 1 \\
\hline & 172 & 16 & 1 & 一 & 1 & 3 & 4 & 7 \\
\hline & 173 & 3 & - & 1 & - & 1 & - & 1 \\
\hline \multicolumn{2}{|c|}{ Subtotal: rollovers } & 38 & 3 & 2 & 1 & 8 & 11 & 13 \\
\hline \multicolumn{2}{|c|}{ All other crashes } & 6 & 1 & 2 & 1 & - & 1 & 1 \\
\hline \multicolumn{2}{|l|}{ Total } & 44 & 4 & 4 & 2 & 8 & 12 & 14 \\
\hline
\end{tabular}

NSW $=$ New South Wales

$\mathrm{VIC}=$ Victoria

$\mathrm{WA}=$ Western Australia

vehicle rollovers. Surprisingly there were only minor differences between the States. Of the 16 vehicle occupants admitted to the spinal injuries unit in Western Australia, 14 had been involved in rollovers: the equivalent figures for Victoria were 16 and 13, and, for New South Wales, 12 and 11. Of more significance is the distinction shown in Table II between metropolitan and non metropolitan cases, with 32 of the 38 crashes taking place outside the respective capital cities.

It is also possible to estimate the relative likelihood of spinal injury to the 3 categories of motor vehicle users. The number of persons injured in each category in the States of New South Wales, Victoria and Western Australia in 1987 was calculated from Road Traffic Accidents Involving Casualties ${ }^{3}$ and compared with the number of spinal injury admissions. The results are given in Table III.

Table III shows that, on the evidence of this survey, the likelihood of an injured person receiving a spinal injury is highest for motor cyclists. However, since this series is incomplete, these ratios are indicative rather than definitive.

\section{Discussion}

\section{Caveat}

There is one necessary caveat to begin this discussion. This project was conducted on a person-to-person request basis since it received no financial support from any source and there is an obvious penalty. The series is incomplete. Only 67 of the 93 cases identified by the spinal injury units were traceable. In the opinion of this author, the major consequence is that, for the methodological reasons stated above, the number of motor vehicle passengers is understated, but there seems no reason to suggest that the other data are skewed in any particular direction. Accordingly, and until a more comprehensive study is completed, it is here thought that this report may serve as a pilot study.

This caveat reinforces in the strongest

Table III Relative risk of spinal injury

\begin{tabular}{lccc} 
& $\begin{array}{c}\text { Motor vehicle } \\
\text { drivers }\end{array}$ & $\begin{array}{c}\text { Motor vehicle } \\
\text { passengers }\end{array}$ & Motor cyclists \\
\hline $\begin{array}{l}\text { Injured and admitted to } \\
\text { hospital }^{3}\end{array}$ & 8,648 & 5,525 & 2,941 \\
$\begin{array}{l}\text { Admitted to spinal injuries } \\
\text { unit }\end{array}$ & 32 & 12 & 18 \\
$\begin{array}{l}\text { Spinal injuries per 1,000 } \\
\text { admissions }\end{array}$ & 3.7 & 2.2 & 6.1 \\
\hline
\end{tabular}


terms the 1987/8 workshop proposals for the creation of a National Registry of Spinal Injuries in Australia. This topic will be discussed later.

\section{Type of road user}

Table I shows that there is a $3: 1$ over-involvement of males in each category of road user. This is the customary Australian ratio and is unremarkable. The age ranges however deserve comment. For both vehicle drivers and vehicle occupants, there is a wide span of ages into the seventh and eighth decades of life. This is not the case for motorcyclists, where there is a span of $18-28$ years and a mean age of 22.7 .

This heavy emphasis on youthful motorcyclists, taken with the probable higher risk of spinal injury implied by the data of Table III, suggests the need for a research project to identify the reasons. For example, it has often been suggested on empirical grounds that young persons should not be permitted to ride the more powerful motorcycles until they have completed a probationary learning period on a low-powered cycle. Unfortunately, the de-identified police accident reports examined in this study often did not include the motorcycle's rating and there are no data to support or refute that suggestion. This would however be a relatively simple and highly appropriate project for an Australian Spinal Injuries Registry.

\section{Day and month}

It is interesting to compare the data of Figures 1 and 2 with the general pattern of road trauma in Australia. Figure 1 demonstrates an over-representation in the weekend leisure period which is similar to the road trauma position generally but the extent of the over-involvement deserves comment. Although there are elevated levels of road trauma on Friday, Saturday and Sunday, this weekend bias in the spinal cord injuries data is very considerably higher.

On the other hand, the data of Figure 2 show a distribution that differs markedly from the wider road trauma position. The feature of note in Figure 2 is the high over-representation of spinal cord injuries in the holiday period between November and February not replicated in the overall road trauma position. ${ }^{3}$

These comments should be treated with caution since the number of cases is small. However, the indications from the data of Figures 1 and 2 seem to support the view that road trauma, and road trauma resulting in spinal cord injury, is - at least in Australia - a disease of leisure. ${ }^{11}$ This suggests the need for a better knowledge of the lifestyle issues that result in elevated levels of this the most serious of all forms of injury.

\section{Type of crash}

The most important finding of this study is the fact that the vast majority of spinal injuries to motor vehicle occupants arise as a consequence of motor vehicle rollovers. The frequency of vehicle rollovers found in this study is higher than that of the earlier study by Toscano ${ }^{12}$ who visited 40 accident sites in the State of Victoria, and reported that the victim's car hit another vehicle in 13 cases; hit a tree or other fixed object in 13 others; and rolled over in the final 14. At first glance, it is hard to reconcile this distribution with the one reported here until it is realised that the categories are not mutually exclusive. A vehicle rollover may commence or culminate in a collision with another vehicle or with a fixed object. Inspection of Table II of this study shows that 13 cases were coded to categories 171 or 173 , ie they 'rolled over and hit a fixed object'.

There is one other possible factor. In the experience of this author, ambulance staff and medical teams tend to record the end point of a collision (eg collision with tree) since this is the perfectly proper starting point for their medical management. By contrast, police investigators tend to trace events from the moment the vehicle left the highway (or even earlier) since this is the appropriate starting point for their accident report. It is therefore to be expected that similar incidents may well be dissimilarly coded in the 2 sets of records. Against this background, the findings of this study and those of the Toscano survey seem more 
comparable. More importantly, both indicate a previously unrecognised high involvement of vehicle rollovers.

This was not an expected finding since vehicle rollovers are relatively infrequent, occurring in only a small percentage of crashes. It was perhaps for this reason that Mackay ${ }^{13}$ concluded '. . . providing an occupant is not ejected and the car does not strike any rigid objects, then rollovers are one of the least injurious of crash types'. This conclusion is presumably based on his surveys of crashes in what is essentially an urban area, in which the infrequent spinal injury case is incorporated within the general hospital system. By contrast, Table II of this study emphasises the important role of country roads in Australia, with 32 of 38 crashes occurring outside the appropriate metropolitan area.

\section{Location of injury}

The data of Figure 2 show a clear bias towards non metropolitan crashes. This suggests that speed (and perhaps road surface) may be significant contributors to the higher incidence of spinal cord injuries in rural crashes. This in turn seems to have strong implications for the structural integrity of vehicles in high speed rural crashes.

It is therefore suggested that the important role of vehicle rollovers in the causation of spinal cord - especially in country areas be recognised.

\section{The mechanism of injury}

Like most exploratory investigations, this study seems to have raised a number of questions that it cannot answer. The most important concerns the mechanism of injury in vehicle rollovers. Mackay (private communication) has suggested that this is almost always the result of a head contact with the roof ... during the rollover when the roof panel is loading the ground and the head is thus constrained so that the inertial mass of the chest, abdomen and pelvis applies a compression load to the neck. Current lap/shoulder belts do not necessarily modify that injury mechanism to any great extent'.

Toscano $^{12}$ took a slightly different view, suggesting that the injury mechanisms should be considered in 2 categories: those wearing seat belts and those not wearing seat belts. In the former category he suggested that the mechanisms were seat belt failures (with an astonishingly large total of 7 cases); and roof or roof pillar collapse, citing 9 cases in these categories; together with a 'small number' of cases from steering wheel or steering column dislodgement.

In the second category, he offers the view that 'persons who do not wear seat belts are prone to develop spinal injuries' and suggests that ' 13 of the patients not wearing seat belts would most likely not have sustained spinal cord injury had they worn their seat belts'.

Unfortunately, the seat belt wearing status of the injured person was not determined in many of the reports examined here so that this study can make only one contribution to that debate. This is to state that the wearing of seat belts does not provide adequate protection against the risk of spinal injury since 23 of the 38 injured vehicle occupants were wearing seat belts. Additional information seems desirable. Toscano puts it thus:- 'Motor vehicle fatality and morbidity due to spinal cord injury will not be reduced unless further research is conducted to define factors in motor vehicle design which contribute to spinal cord injury'.

\section{An Australian Registry of Spinal Cord Injury}

This is perhaps the place to stress the unique potential for an Australian contribution to the prevention of spinal injuries. There are 2 quite separate advantages. First, every case of spinal cord injury in Australia (or almost every case) is admitted to a specialised spinal injuries unit and not to a general hospital. This gives Australia the capability to produce a comprehensive and definitive data set on the incidence and trends of causal factors that result in spinal injury. This could be developed from a National Registry of Spinal Cord Injury with input from each of the specialised units. Such a registry, based on the case histories of patients admitted to the units, would automatically meet the criteria of accuracy, 
currency, relevance and accessibility prescribed almost 20 years ago by Lane. ${ }^{15}$ The content of the records could also be tailored to meet the particular research need, whether the theme be falls on the one hand or traffic injuries on the other. This enormous potential for injury prevention work is the reason why the creation of such a national Registry was the major recommendation from the Menzies Foundation workshops in Perth. ${ }^{17}$

The present paper was, to some extent, fortuitous. The Menzies Workshop showed that about half of all spinal cord injuries arose as a consequence of road crashes. The author, because of his earlier work in road trauma, realised that existing police reports could throw new light on the types of crash which result in spinal cord injuries. An examination of these data was carried out partly because of the potential value of the study but largely to illustrate the type of benefit that could be expected to arise from detailed examination of the data contained in a National Registry of Spinal Cord injuries.
There is a further advantage in a National Registry. The Australian federal system of government leaves scope for legislative and other innovations in the road safety field to be introduced at State level whilst road traffic injury data are also likely to continue to be assembled at State level. This scenario permits innovations by one State to be evaluated using data from another (non participating) State as a control. With this inbuilt advantage, admirably exploited by many workers who evaluated the effectiveness of Australia's pioneering seat belt legislation (see for example Foldvary and Lane $)^{16}$ Australia could be well placed to make a significant and continuing contribution to the important problem of reducing spinal cord injuries.

\section{Acknowledgments}

Thanks are due to both referees for their helpful comments which have been incorporated in the final draft and which have greatly strengthened this paper.

\section{References}

1 Bedbrook G (1987) Keynote address. In: Refshauge W, editor. Towards prevention of spinal cord injury. Menzies Foundation Technical Report 1: 9-12.

2 Wigglesworth EC (1987) Towards solution: a literature review. In: Refshange W, editor. Towards prevention of spinal cord Injury. Menzies Foundation Technical Report 1: 75-85.

3 Australian Bureau of Statistics. Road Traffic Accidents Involving Casualties. ABS Catalogue 9405.0. Canberra (annual).

4 Burke DC (1973) Spinal cord injuries and seat belts. Med J Aust 2: 801-802.

5 Cheshire DJE (1968) The complete and centralised treatment of paraplegia. Paraplegia 6: 59-73.

6 Sutton NG (1973) Injuries of the Spinal Cord: the Management of Paraplegia and Tetraplegia. Butterworths, London.

7 Burke DC (1977) Spinal cord injuries 1976. ANZ J Surg 47: 166-170.

8 Burke DC, Toscano G (1987) Incidence and distribution of spinal cord injury. In: Refshauge W, editor. Towards prevention of spinal cord injury. Menzies Foundation Technical Report 1: 13-47.

9 Mackay M (1982) The prevention of injury in road accidents. In: Tubbs N, London PS, editors. Topical Reviews in Accident Surgery. Wright-PSG, Bristol.

10 Andreassen D (1983) Standard accident definitions: primary accident classes and accident types. Aust Road Res 13(1): 10-24.

11 Wigglesworth EC (1970) Accidents in Australia: the need for research Med J Aust 1: 1113-1120.

12 Toscano $G$ (1986) A study to identify risk factors in the aetiology and cause of traumatic spinal cord paralysis. MD Thesis. University of Melbourne.

13 Mackay M (1987) Kinematics of vehicle crashes. Adv Trauma 2: 21-42.

14 Wigglesworth EC (1981) Death on the roads: road traffic mortality in the Northern Territory 1969-1980. Living in the North: Transactions of the Menzies Foundation 2: 173-178.

15 Lane JC (1972) Statistical information in relation to accidents. Proceedings of the National Road Safety Symposium. Dept Shipping and Transport, Canberra: 42-49.

16 Foldvary LA, Lane JC (1974) The effectiveness of compulsory wearing of seat-belts in casualty reduction. Accid Anal Prev 6: 59-81.

17 Wigglesworth EC (1988) Towards prevention of spinal cord injury: the role of a national register. Paraplegia 26: 389-392. 